Observations de la comète périodique Brooks (1889 V) $1896 \mathrm{VI}$

faites à l'observatoire de Rio, par M. L. Cruls.

\begin{tabular}{|c|c|c|c|c|c|c|c|c|c|c|c|}
\hline 1896 & T. m. Rio. & $\Delta a$ & $\Delta \delta$ & Cp. & $\alpha$ app. & $\log p . \Delta$ & $\delta$ app. & $\log p \cdot \Delta$ & Red. & A l. app. & * \\
\hline iill. 30 & $9^{\mathrm{h}} 25^{\mathrm{m}} 14^{\mathrm{s}}$ & $-4^{m} \quad 2 \cdot 96$ & $+1 x^{\prime} 24 \% 0$ & 5.5 & $22^{h} \cdot 3^{8^{m}} \cdot 20^{5} \cdot 09$ & $9.729 n$ & $-18^{\circ} 30^{\circ} \quad 6_{4}^{\prime \prime}$ & $0.3^{66} 6_{n}$ & +3.87 & +21.0 & \\
\hline oth I & $\begin{array}{lll}8 & 54 & 25\end{array}$ & -433.06 & +87.7 & $4 \cdot 4$ & $22 \quad 37 \quad 50.03$ & & - I $833 \quad 22.4$ & & +3 & & \\
\hline 4 & 92030 & -531.40 & +255.5 & 6.6 & $22 \quad 36 \quad 51.75$ & & $-183^{8} 34.4$ & $0.33 \mathrm{In}$ & +3.97 & $+21 \cdot 3$ & \\
\hline 12 & 9 I० 33 & +2 I 0.44 & $-433 \cdot 5$ & 6.6 & $2233 \times 4.60$ & $9.69 I_{n}$ & $-185^{2} 47.5$ & $0.272_{n}$ & +4.16 & +20.6 & \\
\hline
\end{tabular}

Positions moyennes des étoiles de comparaison pour i896.0.

\begin{tabular}{|c|c|c|c|}
\hline$*$ & $\alpha$ & $\delta$ & Autorité \\
\hline 1 & $22^{\mathrm{h}} 42^{\mathrm{m}} 19 . \mathrm{s} 8$ & $-18^{\circ} 4 I^{\prime} 5^{\prime \prime \prime} \cdot 2$ & An., rapp. (6.6 comp.) \& $\operatorname{Rad}_{3} 6098$ \\
\hline 2 & $2231 \quad 0.01$ & $-1848 \quad 34.6$ & $\operatorname{Rad}_{3} 6058$ \\
\hline
\end{tabular}

Notes.

Ces observations ont été faites par MM. L. Cruls et $\quad 30$ Juillet. Très-faible nébulosité d'environ I' de dia$H$. Morize, astronome, avec l'équatorial de 9 pouces. mètre, avec noyau de $\mathbf{I}^{\mathbf{m}}$. comète :

Voici des notes prises sur l'aspect pbysique de la

28 Juillet. Noté une nébulosité extrêmement faible, que l'êtat du ciel empêche d'observer.

Obșervatoire de Rio, 9 Oct. 1896.
4 Août. Éclat semble avoir diminué.

12 Août. Éclat légèrement augmenté, noyau de $\mathbf{I}^{\mathbf{m}}$, avec intensités lumineuses intermittentes.

\title{
Continuazione della effemeride del pianeta (345) Tercidina
} per $2^{\text {h }}$ di tempo medio di Berlino.

Vedi Astr. Nachr. No. 3387 .

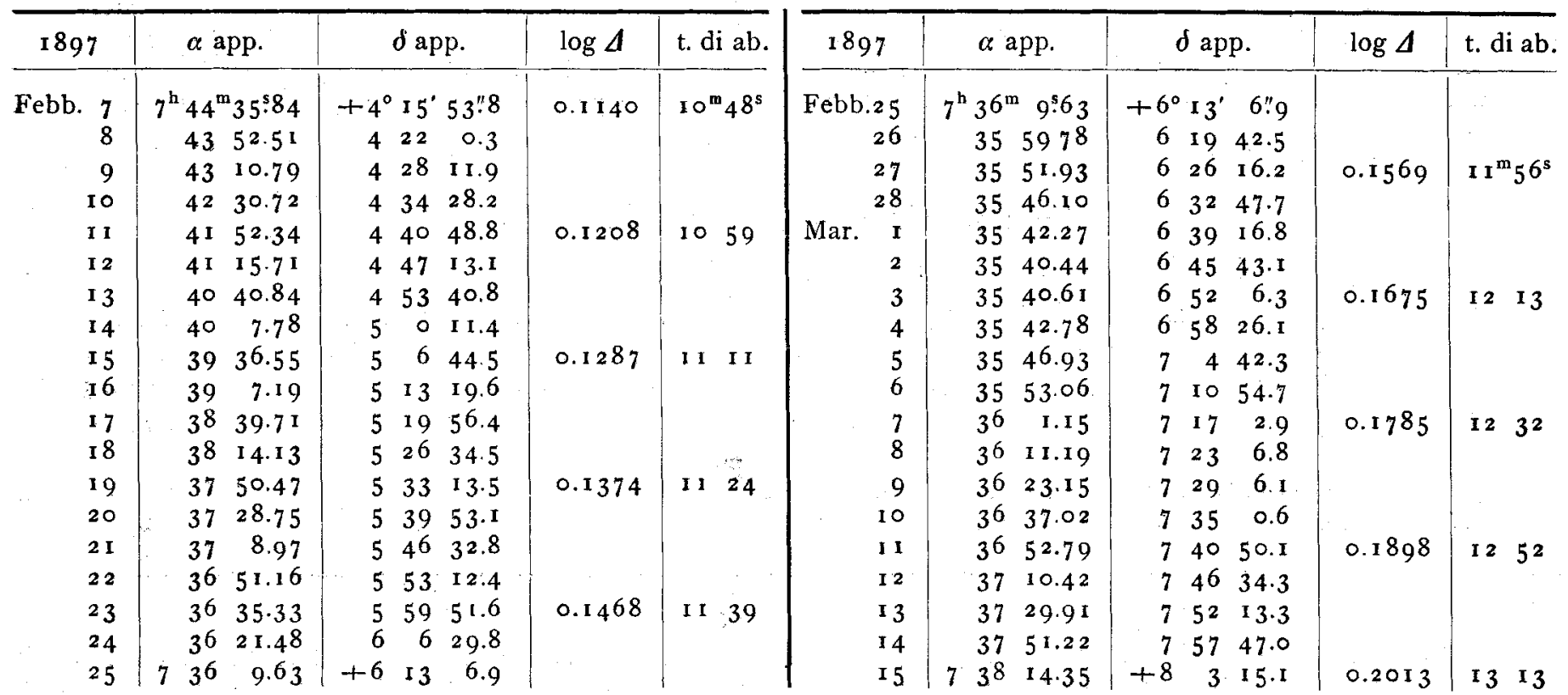

La suddetta effemeride fu continuata dal Dr. Viaro a Padova.

Gli $(\mathrm{O}-\mathrm{C})$ dati in A. N. $339 \mathrm{x}$, e nel fascicolo 5 delle Pubblicazioni di Arcetri pag. 16 , si mantengono sempre negli stessi limiti $\left(+3^{s}-9^{\prime \prime}\right)$ come lo provano ulteriori osservazioni di Düsseldorf, Roma ed Arcetri.

Arcetri-Firenze, 2 Febbr. 1897.

A. Abetti. 